\title{
Clinical study of various risk factors associated with intrauterine fetal death
}

\section{Ashok Kumar K., Ravindra Kanakeri, Bharathi Anjanappa*}

Department of Obstetrics and Gynecology, ESIC MC PGIMSR and Model Hospital, Rajajinagar, Bangalore, Karnataka, India

Received: 10 November 2017

Accepted: 16 November 2017

*Correspondence:

Dr. Bharathi Anjanappa,

E-mail: bharathiworld84@gmail.com

Copyright: (C) the author(s), publisher and licensee Medip Academy. This is an open-access article distributed under the terms of the Creative Commons Attribution Non-Commercial License, which permits unrestricted non-commercial use, distribution, and reproduction in any medium, provided the original work is properly cited.

\begin{abstract}
Background: The death of a fetus is one of the unhappy events in the field of obstetrics. It is really distressing when it occurs without warning in a pregnancy that has previously entirely normal. It is thus vital to identify specific probable causes of fetal death to determine the risk of recurrence, prevention or corrective action.

Methods: A prospective observational study was conducted in ESIC MC and PGIMSR, Rajajinagar, Bangalore, Karnataka, India. All cases of intrauterine fetal death confirmed either with ultrasound or on clinical examination by absence of fetal heart rate and fetal movements were studied. The age, parity, literacy, socio-economic status was recorded. Detailed history, clinical examination, associated conditions. Mode of delivery and details of the fetus and their placentas were noted. They were followed for 3 days for complications.

Results: Mean maternal age was $26.03 y$ yrs, $98.5 \%$ of the women were booked cases, $82 \%$ belonged to lower middle class.16.39\% of the women had hypertensive disorder of pregnancy, $4.91 \%$ had gestational diabetes, $9.8 \%$ had abruption placentae, $9.8 \%$ had oligohydramnios and $1.63 \%$ had polyhydramnios $4.9 \%$ were $\mathrm{Rh}$ isoimmunisation, $1.9 \%$ had twin pregnancy, 3.27\% had PROM, 6.6\% had cord accidents, $21 \%$ had anomalous fetus, $3.27 \%$ foetuses had non immune hydrops, $19.67 \%$ of IUDs were unexplained.

Conclusions: Unexplained causes, PIH and abruptio placentae were major causes of IUFD. Significant proportion of IUFD due to PIH and abruption placenta is preventable by regular antenatal care and timely intervention. Despite advances in diagnostic and therapeutic modalities large number of fetal deaths remain unexplained. Poverty, illiteracy, unawareness and inaccessibility may be some of the reasons for unexplained IUFD.
\end{abstract}

Keywords: Antenatal care, Causes, Intrauterine fetal death, Prevention, Risk factors

\section{INTRODUCTION}

The death of a fetus is one of the unhappy events in the field of obstetrics. It is really distressing when it occurs without warning in a pregnancy that has previously seemed entirely normal.

It is an event that challenges both the medical and personal skill of the doctor. It is thus vital to identify specific probable causes of fetal death to determine the risk of recurrence, prevention or corrective action.
Fetal death is, defined by the WHO in 1950 and revised by the working group formed by the American Academy of Pediatrics and ACOG in 1988 as death prior to the complete expulsion or extraction from its mother of a product of human conception, irrespective of the duration of pregnancy and which is not an induced termination of pregnancy. ${ }^{1,2}$

Early fetal death occurs less than 20 weeks, intermediate fetal eats occurs from 20-27 weeks, late fetal deaths occur at 28 or more completed weeks of gestation. ${ }^{3}$ 
Fetal loss is a sensitive indicator of maternal care during antenatal period. It directly reflects the obstetrician's vigilance kept during particular pregnancy. For an obstetrician, documentation of primary event or factor which has led to fetal death is of paramount importance. Only when probable etiology is known the patient can be given guidance for the treatment, prevention and recurrence as required.

Illiteracy, poor socioeconomic condition and social status of women and misbelieves are important contributory factors responsible for higher fetal mortality rate, as all these prevent women to go to the hospital for health check-up.

One should appreciate that the grief response following stillbirth is severe and is similar to that following loss of an adult family member. It is probably most traumatic experience women undergoes in her life and it takes about months for a woman to return to normal routine life.

Since many attempts have been made to lower the death of new born babies with the help of rapidly advancing intensive neonatal care unit, neonatal death rate is reduced in developed countries. A small reduction in perinatal mortality rate is due to reduction in the infant mortality rate and not because of fetal mortality. So,attention is now drawn towards the unborn babies in utero in order to get a live baby and so that perinatal mortality can be further reduced.

Newer techniques of diagnosis and a better understanding of pathophysiology have led to the determination of cause of death in a greater proportion of fetal deaths than in the past.

The perinatal mortality in India presently is $30 / 1000$ births (2014), in state of Karnataka is $40 / 1000$ births. Prior stillbirth is associated with a twofold to 10-fold increased risk of stillbirth in the future pregnancy. The risk depends on the etiology of the prior stillbirth, presence of fetal growth restriction, gestational age of the prior stillbirth,and race. Categorization of the cause of the initial stillbirth will allow better estimates of individual recurrence risk and guide management. A history of stillbirth also increases the risk of other adverse pregnancy outcomes in the subsequent pregnancy such as placental abruption, caesarean delivery, preterm delivery, and low birth weight infants. Ante partum fetal surveillance and fetal movement counting are also mainstays of post stillbirth pregnancy management. ${ }^{4,5}$ Therefore we conducted the following study with following objectives.

Objectives of present study were to know the clinical risk factors of intra-uterine fetal death, to know the probable etiology for antepartum and intrapartum fetal deaths, and to study the role of antenatal care in prevention of intrauterine fetal deaths.

\section{METHODS}

Cases of intra-uterine fetal death attending the ESIC MC and PGIMSR, Rajajinagar, Bangalore between September 2014 to September 2016 were included in the study. Minimum number of cases were 50 cases.

A prospective observational study was undertaken. The cases of intra-uterine fetal death either with ultrasound reports proving IUD or diagnosed on clinical examination by absence of fetal heart rate and fetal movements were studied.

\section{Inclusion criteria}

All cases of IUD with gestational age $>20$ weeks and $<42$ weeks period of gestation.

\section{Exclusion criteria}

- All cases of IUD with gestational age $<20$ weeks and $>42$ weeks

- Molar pregnancy.

When a patient comes with complaints of absent fetal movements or comes with an ultrasound report showing intra- uterine fetal death; the age, parity, literacy, socioeconomic status were recorded.

Detailed obstetric history, details about present complaints and duration of present pregnancy, past obstetric performances and outcomes (including previous abortions, previous IUFD, associated toxemias, etc.,) were studied

In the present pregnancy, details of ante-natal check-ups, medical illness, presence of antepatum hemorrhage, pregnancy induced hypertension, eclampsia, severe anemia and other significant illness were also noted. Those patients who had attended antenatal clinic atleast thrice before delivery were considered booked cases.

Clinical examination is done. General condition of the patient is noted. On per abdomen examination height of uterus, tone of uterus, feeling of "egg shell crackling sign", presentation and position of fetus, liquor and its quantity noted. Absent FHS is noted.

In per speculum examination any bleeding from os or prolapse of cord noted, liquor- colour and smell were noted. If the patient has come with history of absent fetal movements and on examination FHS is not localized USG examination is done to confirm the diagnosis of intrauterine fetal death.

Mode of delivery and birth weights of fetuses were noted. All the fetuses were examined for any malformations and each placenta checked for its appearance, weight, retroplacental clot/infarcts and calcification. 
All patients were followed for 3 days for post-delivery complications.

The following investigations were done for the patients.

- Hemoglobin\%, Urine for albumin, sugar, microscopy

- HIV, HBsAg, VDRL, Blood group and Rh type, FBS, PPBS and GTT

- Ultrasonography

- Bleeding time, clotting time and clot retraction time when indicated.

- Prothrombin time and activated partial thromboplastin time in required cases

- Placenta for histopathological examination

- Fetal autopsy (if consent is given).

\section{RESULTS}

Table 1 describes demographic details of the study. In the present study mean maternal age was 26.03 years (Mean \pm SD: $26.03 \pm 4.72$ ). Out of 61 women, $1.6 \%$ were $<20$ years, $78.7 \%$ were $20-30$ years, $18 \%$ were $31-40$ years and $1.6 \%$ were $>40$ years of age (Table 1 ).

Table 1: Demographic details.

\begin{tabular}{|lll|}
\hline $\begin{array}{l}\text { Parameters } \\
\text { Age (yrs) }\end{array}$ & $\begin{array}{c}\text { No of patients } \\
(\mathbf{N}=61)\end{array}$ & Percentage \\
\hline$<20$ & 1 & 1.6 \\
\hline $20-30$ & 48 & 78.7 \\
\hline $31-40$ & 11 & 18.0 \\
\hline$>40$ & 1 & 1.6 \\
\hline Socio-economic status & \\
\hline Lower Middle & 50 & 82.0 \\
\hline Upper Middle & 11 & 18.0 \\
\hline Registration of antenatal visits & \\
\hline Booked cases & 60 & 98.4 \\
\hline Unbooked cases & 1 & 1.6 \\
\hline Parity & & \\
\hline Primi & 30 & 49.2 \\
\hline Multi & 31 & 50.8 \\
\hline
\end{tabular}

Out of 61 women 50 (82\%) women belong to lower middle class and $11(18 \%)$ belongs to upper middle class. $60(98.4 \%)$ women were booked and 1 (1.6\%) was unbooked. $30(49.2 \%)$ women were primis and 31 $(50.8 \%)$ women were muligravidas.

Table 2 describes different characters of IUDs like gender, weight and gestational age of foetuses and mode of delivery. In present study, out of 61 fetuses $-52.5 \%$ were female and $47.5 \%$ were male foetuses. Weight of the foetuses were as follows: $29(47.5 \%)$ weighed $<1000$ grams, $12(19.7 \%)$ weighed $1001-1500$ grams, $6(9.8 \%)$ weighed 1501-2000 grams, 6(9.8\%) foetuses weighed 2001-2500 grams, 6(9.8\%) were 2501-3000 grams and 2 (3.3\%) weighed > 3000 grams. Mean weight of the fetus in present study was 1324 gms (Mean \pm SD: $1324.59 \pm 804.36)$.

Table 2: Details of IUDS.

\begin{tabular}{|lll|}
\hline $\begin{array}{l}\text { Parameters } \\
\text { Gender of fetuses }\end{array}$ & No fetuses & Percentage \\
\hline Female & 32 & 52.5 \\
\hline Male & 29 & 47.5 \\
\hline Fetal weight (Gms) & & \\
\hline$<1000$ & 29 & 47.5 \\
\hline $1000-1500$ & 12 & 19.7 \\
\hline $1500-2000$ & 6 & 9.8 \\
\hline $2000-2500$ & 6 & 9.8 \\
\hline $2500-3000$ & 6 & 9.8 \\
\hline$>3000$ & 2 & 3.3 \\
\hline Gestational age (weeks) & \\
\hline $21-28$ & 20 & 32.8 \\
\hline $28-32$ & 16 & 26.2 \\
\hline $32-37$ & 14 & 23.0 \\
\hline $37-40$ & 11 & 18.0 \\
\hline $40-42$ & 0 & 0.0 \\
\hline Mode of delivery & & \\
\hline PTVD & 46 & 75.4 \\
\hline FTVD & 12 & 19.67 \\
\hline LSCS & 2 & 3.27 \\
\hline Assisted breech & 1 & 1.6 \\
\hline
\end{tabular}

Gestational age of the foetuses were-20 (32.8\%) belongs to $21-28$ weeks of gestation, $16(26.2 \%)$ belongs to $29-32$ weeks, $14(23 \%)$ belongs to $33-37$ weeks and $11(18 \%)$ belong to 38 to 40 weeks of period of gestation $(\mathrm{P}=30.79 \pm 5.30)$.

Mode of delivery in present study, out of 61 women-46 $(75.4 \%)$ women had preterm vaginal delivery, 12 $(19.67 \%)$ women had full term vaginal delivery, 2 (3.27\%) women had LSCS, and 1 (1.6\%) woman had assisted vaginal breech delivery. Indications for LSCS were previous LSCS with scar tenderness and twin with one fetus was fetal demise.

Table 3: Clinical risk factors associated with fetal demise.

\begin{tabular}{|lll|}
\hline Factors associated & No. of patients & $\%$ \\
\hline Unexplained & 12 & 19.67 \\
\hline Abruption placenta & 6 & 9.8 \\
\hline Cord accidents & 4 & 6.6 \\
\hline $\begin{array}{l}\text { Hypertension related } \\
\text { complications }\end{array}$ & 10 & 16.4 \\
\hline Diabetes (GDM+Overt) & 3 & 4.92 \\
\hline Oligohydramnios & 5 & 8.19 \\
\hline PROM & 2 & 3.27 \\
\hline Rh isoimmunisation & 3 & 4.9 \\
\hline Congenital anomalies & 13 & $21 \%$ \\
\hline Non-immune hydrops & 2 & 3.27 \\
\hline Polyhydramnios & 1 & 1.67 \\
\hline Total & 61 & 100.0 \\
\hline
\end{tabular}


Table 3 represents the clinical risk factors associated with fetal demise.

In present study, 12 (19.67\%) IUD's were unexplained, 6 (9.8\%) IUD's were due to abruption placentae, 4 (6.6\%) were due to cord accidents, $10(16.4 \%)$ were due to Hypertension related complications, 3 (4.92\%) were due to diabetes, $5(8.19 \%)$ were due to severe oligohydramnios, $2(3.27 \%)$ were due to premature rupture of the membranes, $3(4.9 \%)$ were due to $\mathrm{Rh}$ isoimmunisation, $13(21 \%)$ were having major congenital anomalies, $2(3.27 \%)$ were having nonimmune hydrops and $1(1.67 \%)$ was due to polyhydramnios.

Table 4: Maternal risk factors associated with IUD.

\begin{tabular}{|lll|}
\hline Maternal risk factors & No. of patients & $\%$ \\
\hline $\begin{array}{l}\text { Hypertension related } \\
\text { complications }\end{array}$ & 10 & 62.5 \\
\hline Diabetes (GDM+Overt) & 3 & 18.75 \\
\hline Rh isoimmunisation & 3 & 18.75 \\
\hline Bicornuate uterus & 1 & 6.25 \\
\hline Septate uterus & 1 & 6.25 \\
\hline Total & 16 & 100 \\
\hline
\end{tabular}

\section{Maternal risk factors associated with IUD}

In present study, $10(62.5 \%)$ of women had hypertension related complications. $3(18.75 \%)$ were diabetics. 3 $(18.75 \%)$ had $\mathrm{Rh}$ isoimmunisation, 1 (6.25\%) had bicornuate uterus and $1(6.25 \%)$ had septate uterus (Table 4).

Table 5: Placental causes.

\begin{tabular}{|lll|}
\hline Placental causes & No. of women & $\%$ of women \\
\hline Abruption placenta & 6 & 60 \\
\hline Retroplacental clot & 1 & 10 \\
\hline Intraplacental clot & 1 & 10 \\
\hline Unhealthy placenta & 2 & 20 \\
\hline Total & 10 & 100 \\
\hline
\end{tabular}

In present study, out of 61 women 10 had placental causes as the reason for fetal demise. Out of $10,6(60 \%)$ had abruption placenta. $1(10 \%)$ had retroplacental clot 1 (10\%) had intra placental clot and $2(20 \%)$ had unhealthy placenta (Table 5).

In present study, $13(21.3 \%)$ fetuses had associated congenital anomalies.

Following were anomalies found in present study

$2(15.4 \%)$ anencephaly, $1(7.69 \%)$ cystic hygroma, 1 $(7.69 \%)$ encephalocele, $1(7.69 \%)$ holoprocencephaly, 1 (7.69\%) spinabifida, 1 (7.69\%) prunbelly syndrome, 3 $(23.1 \%)$ multiple anamalies, $1(7.69 \%)$ agenesis of corpus collasum, $1(7.69 \%)$ extended ascitis, 1 (7.69\%) bilateral renal dysplasia (Table 6).
Table 6: Fetal congenital anomalies.

\begin{tabular}{|lll|}
\hline Congenital anomalies & $\begin{array}{l}\text { No. of } \\
\text { women }\end{array}$ & $\begin{array}{l}\text { \% of } \\
\text { women }\end{array}$ \\
\hline Anencephaly & 2 & 15.4 \\
\hline Cystic hygroma & 1 & 7.69 \\
\hline Encephalocoele & 1 & 7.69 \\
\hline Holoprocencephaly & 1 & 7.69 \\
\hline Spina bifida+hydrocephalus & 1 & 7.69 \\
\hline Prunbelly syndrome & 1 & 7.69 \\
\hline Multiple anomalies & 3 & 23.1 \\
\hline Agenesis of corpus callosum & 1 & 7.69 \\
\hline with dilated ventricles & 1 & 7.69 \\
\hline Extended ascites & 1 & 7.69 \\
\hline Bilateral renal dysplasia & 1 & 100 \\
\hline Total & 13 & \\
\hline
\end{tabular}

In this study, abruption placenta associated with gestational age.

Out of 6 women, $2(3.27 \%)$ preterm vaginal delivery with weight $1000-1500 \mathrm{gm}, 3(4.91 \%)$ preterm vaginal delivery with weight $1501-2000 \mathrm{gm}, 1(1.63 \%)$ had Full term vaginal delivery with weight 2501-3500 gms (Table 7).

Table 7: Abruptio placenta with birth weight with gestational age.

\begin{tabular}{|lllll|}
\hline Weight (grams) & Term & Pre term & No. & $\%$ \\
\hline $1000-1500$ & - & 2 & 2 & 3.27 \\
\hline $1501-2000$ & - & 3 & 3 & 4.91 \\
\hline $2001-2500$ & - & - & - & - \\
\hline $2501-3500$ & 1 & - & 1 & 1.63 \\
\hline$>3500$ & - & - & - & - \\
\hline Total & 1 & 5 & 6 & 9.83 \\
\hline
\end{tabular}

\section{DISCUSSION}

Maximum number of women in present study group belongs to the age group of 20-30 yrs and lower middle class.

Causes of intrauterine fetal demise in present study were hypertensive disorders of pregnancy which contributes to $16.39 \%$, diabetes in $4.9 \%$ of cases, abruption placenta in $9.8 \%$ of cases, oligohydramnios in $8.1 \%$ of cases, Polyhydramnios in $1.6 \%$ of cases, $\mathrm{Rh}$ isoimmunisation in $4.9 \%$ of cases, multiple pregnancy with singleton pregnancy was $3.3 \%$ of cases, PROM in $3.3 \%$ of cases, cord accidents in $6.55 \%$ of cases, congenital anomalies in $21 \%$ of cases, nonimmune hydrops fetalis in $3.3 \%$ of cases, unexplained in $19.7 \%$ of cases.

The hypertensive disorders of pregnancy in IUD was in Safarzadeha et al $14.1 \%$, Chippa S et al $24.39 \%$ and Yogesh et al 17\%. and in present study $16.39 \%$, which was comparable to Yogesh et al. ${ }^{6-8}$ The diabetes among IUD's in Safarazadeha et al was $12.76 \%$, in Yogesh et al 
$1 \%$ and that of in Nayak SR et al is $10.71 \%$. diabetes in present study was $4.91 \%$. $^{6,8,9}$

\section{Abruptio placentae and IUD}

The abruption placentae in Swapnil et al study was $7.28 \%$, Yogesh et al study $12 \%$, and Nayak S R et al is $10.71 \%$. In present study, it was $9.83 \%$, which is correlating with Nayak SR et al study. ${ }^{8-10}$

\section{Oligohydramnios and IUD}

The incidence of oligohydromnia in Swapnil et al study was $6.28 \%$, Yogesh et al study is $3 \%$, and Nayak SR et al is $7.14 \%$. In the present study it was $8.19 \%$, which is similar to Nayak SR et al. ${ }^{9,10}$

\section{Polyhydramnios and IUD}

In the present study the incidence of polyhydramnios (1.63\%) was comparable to Nayak et al (3.57\%). ${ }^{9}$

\section{Rh isoimmunisation and IUD}

The $\mathrm{Rh}$ isoimmunisation as a cause of fetal demise was found to be $4.8 \%$ in Sangeetha et al, $1 \%$ in Anjali et al study and $2.64 \%$ in Shaheen $\mathrm{S}$ et al and $4.9 \%$ in our study which is similar to with Sangeetha et al study.,11,12

\section{Multiple pregnancy and IUD}

Multiple pregnancy in IUD was $1.9 \%$ inn Anjali et al, and was $3.3 \%$ in present study. ${ }^{11}$

\section{PROM and IUD}

Premature Rupture of membranes was found in Nayak SR et al study in about $3.57 \%$ of cases which is similar to our study $3.27 \%$. $^{9}$

\section{Cord accidents and IUds}

Cord accidents in Swapnil et al study was 2.8\%, Anjali et al study is $1.90 \%$, and Yogesh et al is $4 \%$. In the present study it was $6.55 \%$, which is correlating with Yogesh et al study. ${ }^{8,11}$

\section{Congenital anomalies of the fetus and IUD}

Congenital Anamalies in Sangeetha et al study was $7.31 \%$, Shaheen $\mathrm{S}$ et al study is $19.86 \%$, and Ruth C et al is $14 \% .^{7,12,13}$ In the present study it was $21 \%$, which is comparable to Shaheen $\mathrm{S}$ et al. ${ }^{12}$

\section{Nonimmune hydrops and IUD}

In our study the incidence of non immune Hydrops was $3.27 \%$ which is comparable to Choudri A et al study $(2.1 \%){ }^{11}$

\section{Unexplained causes for IUD}

Unexplained cause in Shaheen $\mathrm{S}$ et al study was $6.2 \%$, $35 \%$ in Yogesh et al and $19.1 \%$ Choudri A et al..$^{8,11,12}$ In our study it was $19.67 \%$, which is correlating with Choudri A et al study. ${ }^{11}$

\section{CONCLUSION}

In conclusion PIH (hypertensive disorders of pregnancy) abruption placenta and congenital anamolies were the leading causes of the IUFD.

Significant proportion of IUFD due to PIH and abruption placenta is preventable by regular ante natal care and timely intervention and treatment for PIH.

Even an attempt to prevent IUFD in PIH, abruptio placenta may cause IUFD because of its unpredictable severity.

Congenital anomalies are unavoidable cause of IUD. But treatment for open neural tube defects may be prevented by proper pre-conceptional counselling and folate supplementation throughout pregnancy.

Despite advances in diagnostic and therapeutic modalities large number of foetal deaths remain unexplained, even with proper antenatal care. Socio- cultural background, poverty, illiteracy, unawareness and inaccessible health care is some of the reasons that predispose women to IUFD and still birth.

\section{ACKNOWLEDGEMENTS}

Authors would like to thank for staff, patients, colleagues, postgraduate students for their contribution to the work. Author also would like to thank Dr. Renuka Ramaiah, Dr. Rachita Biswas, Dr. Jitendra Kumar, and Dr. Deepak Kumar for their contribution to the present study.

Funding: No funding sources

Conflict of interest: None declared

Ethical approval: The study was approved by the Institutional Ethics Committee

\section{REFERENCES}

1. American Academy of Pediatrics and the American College of Obstetricians and Gynaecologists; Guidelines of Perinatal care, $5^{\text {th }}$ ed. Washington DC, AAP an ACOG;2002.

2. Donald I. Practical Obstetric Problems. $6^{\text {th }}$ Ed. BI Publications Pvt Ltd;2006.

3. Branch DW. Immunologic disease and fetal death. Clin Obstet Gynecol. 1987 Jun 1;30(2):295-311.

4. Reddy UM. Prediction and prevention of recurrent stillbirth. Obstet Gynecol. 2007 Nov;110(5):1151-63. 
5. K. Park, Park's Textbook of preventive and social medicine. $18^{\text {th }}$ ed. Banarsidas Bhanot Publishers;2005.

6. Safarzadeh A, Ghaedniajahromi M, Ghaedniajahromi M, Rigi F, Massori N. Intra uterine fetal death and some related factors: A silent tragedy in Southeastern Iran. J Pain Relief. 2014;3:1.

7. Chippa S, Reddy VSPK, Bhavani N, Mukhopadhyay B, Giri A, Sathineedi A. Study of intrauterine fetal death. Int $\mathbf{J}$ Recent Trends Sci Technol. 2014Oct;12(3):624-6.

8. Rathava YR, Mehta LR, Purohit P, Narola DR, Munshi SP, Patel RV. Intra uterine fetal death: an observational study. Int J Scient Res. 2013 Nov; 2(11):388-90.

9. Nayak SR, Garg N. Determination of antepartum fetal death. J Obstet Gynecol India. 2010 Dec;60(6):494-7.
10. Patel S, Thaker R, Shah P, Majumder S. Study of cause and complications of IUFD. Int $\mathrm{J}$ Reprod Contracept Obstet Gynecol. 2014 Dec;3(4):931-5.

11. Choudhary A, Gupta V. Epidemology of intrauterine fetal deaths: A study in tertiary referral centre in Uttarakand. IOSR JDMS. 2014 Mar;13(3 II):03-06.

12. Shahgufta $S$, Shanaz A. Causes of Intrauterine foetal death. J Postgraduate Med Ins. 2006,20(3):239-242.

13. Fretts RC. Etiology and prevention of stillbirth. Am J Obstet Gynecol. 2005;193:1923-35.

Cite this article as: Kumar AK, Kanakeri R, Anjanappa B. Clinical study of various risk factors associated with intrauterine fetal death. Int J Reprod Contracept Obstet Gynecol 2017;6:5293-8. 